\title{
Utilitarian Use of Social Media Services: A Study on Twitter
}

\author{
Dicle Berfin Köse \\ University of Jyväskylä \\ dicle.b.kose@jyu.fi
}

\author{
Alexander Semenov \\ University of Jyväskylä \\ alexander.v.semenov@jyu.fi
}

\author{
Tuure Tuunanen \\ University of Jyväskylä \\ tuure@tuunanen.fi
}

\begin{abstract}
This paper applies structuration theory (ST) and service dominant logic (SDL) as lenses to study different uses of information systems (IS). We argue that resources provided by IS may be combined and reproduced by appropriating them for different purposes than the design purposes of the IS. The study provides empirical data and analysis to showcase the use of resources for utilitarian purposes in the context of social media services (SMS). Through an analysis of sponsored tweets on Twitter, we show that users employ implicit and explicit resources for utilitarian outcomes. Our findings imply that users create their own service through appropriation of resources available in the social context of service use; hence, they induce different adaptations of the information system.
\end{abstract}

\section{Introduction}

IS have branched out from organizational contexts and they are now used in different aspects of daily life for various purposes. Examples include but are not limited to social networking services, video games, ecommerce websites, online banking services and crowdsourcing platforms. One important characteristic of these services is that they reside in a sphere in which the service provider has no direct control over how users utilize the information system. In addition, the flexibility that has come with Web 2.0 (i.e., enablement of users as content creators) has provided users the freedom to decide how to use IS according to their own imagination, needs and purposes.

This ability to determine the benefit, and the lack of control in IS use enable their adaption for various purposes. Utilitarian IS may be used for hedonic purposes, hedonic IS may be adapted to utilitarian use; moreover, resources external to IS may contribute to these different uses. One case of such adaption is utilitarian use of SMS for monetary purposes. For instance, some Twitch broadcasters make a living out of streaming their games through tips, subscriptions and even through merchandise or sponsorships [1].
Instagram and Facebook host a growing number of people who earn money by posting advertisements of brands [2, 3]. Facebook is launching its marketplace tool to ease buying and selling as a result of the fact that one quarter of the site's visitors trade on it, and there are more than 450 million buying and selling groups [4].

The mixing of hedonic and utilitarian values in IS is growing, and previous research has looked into effects of hedonic and utilitarian value on technology acceptance (e.g., $[5,6])$, the change of use motivation over time (e.g., [7-9]) and use of the same information system for both hedonic and utilitarian purposes (e.g., $[10,11])$. However, no previous study was found regarding resources conducive to these different uses of IS. Accordingly, the research question of this study is, What resources contribute to utilitarian use of $I S$, particularly SMS?

With this purpose in mind, the study investigates utilitarian usage of Twitter by screening sponsored tweets posted by people. Here people refers to those who are not celebrities and is distinguished by the absence of the "verified" badge provided by Twitter. Sponsored tweets provide monetary gains to their owners; hence, they are a source of utilitarian value in the form of extrinsic rewards. Sponsored content was chosen for analysis instead of other utilitarian use types because today users are bombarded with information and there is increasing concern regarding the transparency of this information and what is genuine content and what is not. Above all, owners of this type of content make use of various resources to receive monetary gains from their social media accounts. Therefore, to study this, we analyzed accounts posting these tweets to extract their profile characteristics and tweeting behavior, which in turn helped identify what resources they used.

The study is explorative in nature; however, it draws on ST [12] and SDL [13, 14] for analysis of the data and presentation of the results. Based on our findings, we argue that utilitarian use of SMS is enabled by resources available within the social context of service use and by the different meanings people attribute to these resources. Different combinations of resources and values result in separate uses of the same service. From that perspective, ST is suitable for analyzing the 
processual change of IS use by treating them as social systems that interplay with their users. On the other hand, SDL provides a motivational perspective (values of the IS users) and concentrates on operating on resources in contrast to controlling resources as in ST [15].

The results inform us about the kinds of resources people employ in the utilitarian use of SMS, particularly in the case of Twitter and sponsored content. Previous literature has focused on usability and functionality in terms of IS features (e.g., TAM studies) and has emphasized the organizational or educational contexts when studying utilitarian use. However, the findings of this study suggest that utilitarian use of IS is not bound to these contexts; moreover, it is also resources external to IS that enable their utilitarian use. The analysis shows that people employ both direct and indirect network externalities together with online identities as resources in the case of sponsored tweets.

We argue that acknowledging the utilitarian input of resources other than IS features is important for several reasons. First, it enhances knowledge on IS use. Second, it provides a new standpoint for IS design and user engagement. And finally, it offers foresight into how IS may diverge from their design purpose.

The paper is organized as follows. In the next section we briefly introduce online advertisements. Thereafter, we provide the theoretical background of the study. This is followed by the research methodology and results. Last, we discuss the findings and our conclusions and consider the study's limitations and potential avenues for future research.

\section{Online advertisements}

The Internet is more or less a level playing field for advertisements, as it provides fair reach to resources; besides, establishing an initial presence online is relatively easy and low cost, and it provides reach to an international audience [16]. Furthermore, online social networks facilitate this usage by providing a platform comprised of networked people. According to The Economist [17], publishing advertisements on social media accounts is a growing business among celebrities. Yet, it is not only the celebrities who get sponsored for advertisements. People who are not of public interest have also started using social media for monetary gains.

Consequently, there is increasing control of online sponsored content. The Federal Trade Commission (FTC) [18] states that online advertisements including those on social media need to incorporate clear and conspicuous disclosures. Furthermore, they elaborate that the disclosure should exist in each advertisement in a space-constrained ad, like those in tweets. Likewise, the Word of Mouth Marketing Association (WOMMA) recommends that, alongside the existence of a material connection between the speaker and the company and/or brand, disclosures should be made not only for ethical and responsible communication but also to avoid monetary, regulatory or legal risks [19].

One way to make money via online accounts is to publish sponsored content (e.g., sponsored tweets). Sponsored tweets are messages posted on Twitter and sponsored by an advertiser to create word of mouth with the aim of reaching potential customers. There is a growing business network around social media advertising; for instance, services such as adly and SponsoredTweets bring together advertisers and advertisement publishers. Relatedly, Park, Lee, Kim and Chung show that online advertisements are more effective when the publisher has a large audience (i.e., has a high number of followers) and is actively engaged with the online social network (i.e., publishes a high number of posts) [20]. Other services (e.g., Hootsuite, quintly) enable brands to measure and boost their social media impact, identify key interacting users, conduct tweet analysis and perform many more activities.

\section{Theoretical background}

Here we review ST [12] and SDL [13, 14] to explain the adaptation of SMS. The term adaptation stands for emergence of new use types in the context of IS. In this explanation, ST helps us understand the processual change of SMS use, and SDL elucidates the role of values and resources in this change.

First, ST was developed by Giddens [12] to explain the recursive change in social systems through reflexive and knowledgeable actions of human agents. It has been applied to IS in many studies that investigate the processual change of IS and IS use by their users' adaptions (see, e.g., adaptive structuration theory [21]).

In our study, we will take on four main concepts of ST: agents, structures, systems and the duality of structure. Agents are the knowledgeable human actors who act purposefully, rationally and by monitoring their actions reflexively. Structures are the rules and resources of a social system. They both enable and constrain people's actions and, at the same time, are recursively formed by these same actions as properties of the system. As for systems, they comprise the relations and regular practices of actors and collectivities that are organized and reproduced in interaction settings. The last concept, duality of structure, considers that the properties of social systems transform recursively as a result of the practices they accommodate; they are both a medium and an outcome of these practices. 
IS are combinations of rules and resources designed for specific purposes. Yet, different configurations of these IS rules and resources suited to given conditions result in different types of uses. In this process, acknowledging the knowledgeable and reflexive nature of human agents provides an understanding of their interpretive uses of IS [22]. At this point, SDL's customer-centric approach to IS provides a better understanding of IS adaption into different uses and their corollary adaptations.

SDL emphasizes customer-determined value through the application of resources for the benefit of a party or the party itself $[13,14]$. According to SDL, value is a judgment of the increase or decrease in the well-being of an entity in some respect and is an experiential concept determined individually and contextually. It is the apprehension of the resource integration process and the result of service experience.

According to SDL, users derive two types of value from IS: utilitarian and hedonic. Utilitarian value is incentivized by IS users' extrinsic motivations $[6,23]$. It is driven by conscious pursuit of intended outcomes [24]. Tasks and accomplishments are prominent for users with utilitarian orientation; hence, they approach IS use rationally [25]. Instead of being an end, IS usage becomes a tool for achieving a goal; therefore, usability and functionality gain importance. Within utilitarian IS, user efficiency and performance are prominent, and hence, utilitarian value is quantifiable in terms of objective measures [26].

On the other hand, hedonic value is driven by intrinsic motivations [6, 23]. It represents activities pursued out of inner interests without external pressures [27]. Hirschman and Holbrook view it as the essence of consumers' psychological experience [28]. They state that it is about emotional arousals, multisensory images and fantasies; in other words, the activity may cause historic imagery through reminders of past events or fantasy imagery by evoking users' imaginations. Moreover, they state that hedonic value is affected by the social aspects of consumer experience; therefore, instead of its objective attributes, what the information system represents gains importance. For these reasons, hedonic value is a subjective concept and difficult to measure [26, 28].

Hedonic or utilitarian, value is determined in use and stems from the application of operant resources that may be transferred through operand resources. Operand resources are physical, static and finite materials and may be manipulated for beneficial use. They are mostly natural resources that become a resource when humans find a use for them. On the other hand, operant resources are intangible competences (i.e., skills and knowledge) that act on operand resources to produce effects. These effects may enhance the value of physical properties or reproduce operant resources [13].

SMS create their own version of social systems with their underlying programming code, relevant end-user license agreements and terms of service [29]. What is more, their flexible nature in terms of the miscellaneous resources they provide enables their adaption for different purposes. Users of these services determine and propose value by utilizing these various resources. The resources they employ may be their own skills and knowledge, or they may also be of an operand nature. As Hilton and Hughes put it, IS embody codified operant resources of the service provider, and these embedded resources become operand resources for the benefit of IS users [30].

Among the resources available on SMS are network externalities, presentation of online identity and features intrinsic to the social media services.

The value consumers derive from a service is dependent upon other agents in the service network [31]. When the value of membership is positively correlated with the number of other users or the network size, those markets are said to exhibit "network effects" or "network externalities" [32]. Network externalities are often conceptualized with two constituents: direct network externalities and indirect network externalities. Direct and indirect network externalities are extrinsic attributes of a service, compared to its intrinsic attributes such as its functionalities, technical specifications or accessibility [33].

Direct network externalities stem from other users of the service [31, 34]. In the context of SMS, it may be conceptualized as, for example, the number of contacts on the service. Zheng, Salganik and Gelman found that the median number of acquaintances one has is 610 , with $90 \%$ of the population having an expected number of contacts between 250 and 1710 , according to their analysis of 1370 individuals in American society [35]. However, through SMS, the number of people one can reach or have in one's circle may be tens of thousands or even millions.

Indirect network externalities occur as a result of complementary services related to the original service $[31,34]$. These complementary services enhance perceived value for users, as they augment available actions [36]. For instance, the Twitter developer network offers various services by making use of Twitter data and developer tools. One example is quintly, which provides services for follower and tweet analysis, interaction analytics, customer care metrics and identification of key interacting users [37]. Another example is Hootsuite, which offers services for measuring and boosting Twitter impact [38].

Finally, online identity is another important resource on SMS. This is because these services provide a 


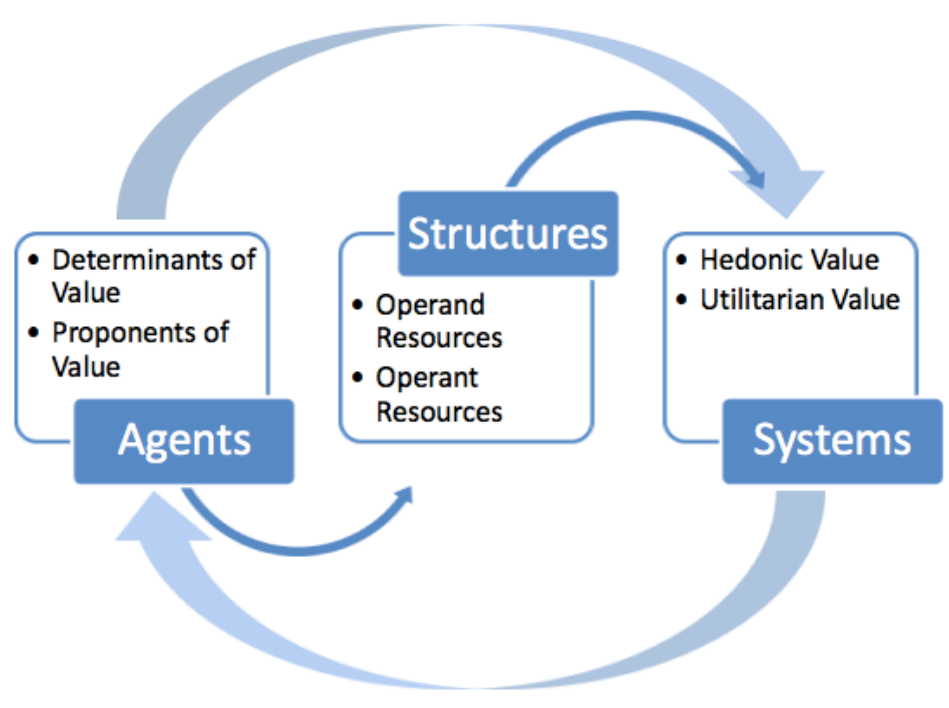

Figure 1. Adaptation of social media services

separate medium than the offline world for identity production. Their features enable the portrayal of different identities formed through concepts of lifestyle, connections and media consumption [39]. In Sundén's words, they allow members to "type oneself into being" [40]. As Miller indicates, one type of online identity presentation is self-promotional, which is similar to the display of an electronic curriculum vitae or of services provided by the person [41]. However, this display is dependent upon the sense of an actual and imagined audience [39]. According to the imagined audience, profile owners use various methods to target different followers, balance authenticity and perform selfcensorship [42].

By recognizing these resources and applying their own competencies, agents use SMS for hedonic or utilitarian values. Proliferation of these uses, in turn, results in their acceptance and integration into the service. This is a recursive process in which users' activities on the service change the service, which in turn affects again how people employ the information system. Figure 1 above depicts this process: Users of the social media service become proponents and determinants of value, and according to the type of their usage, they employ different sorts of resources. The social media service, in turn, provides hedonic or utilitarian value according to how it is used. Users' choice of resources is depicted with the arrow from agents to structures, and the employment of varying resources to deliver hedonic or utilitarian value is indicated with the arrow from structures to systems. Yet, it should be noted that these arrows do not represent causal relationships; rather they indicate that users "determine/provide" value according to the resources they "identify." The loop displays the interplay between social media users and the service. As users' different employments proliferate, they become part of the service's value proposition.

\section{Research methodology}

The methodology of this research study analyzed data directly extracted from Twitter. First, we collected data in two different ways to encompass various uses. Second, we applied filtering and randomization techniques due to the amount of collected data so that it is feasible to manually analyze the data set. The following sections describe the methodology in detail.

\subsection{Data collection}

Data collection was done in two steps. The first step involved collecting Twitter accounts created in the name of G20 leaders and the top 21 Twitter accounts with the highest number of followers according to Twitter Counter [43]. These accounts were collected because public identities were deemed to be resources for online identity presentation on SMS. The second step involved streaming tweets that contained advertisement hashtags.

For the first step, the collection of accounts and tweets for public personas was conducted during the third week of February 2017. In order to extract Twitter users' screen names, we used the Twitter API function "users/search" [44]. This API function returns 1000 accounts with a matching full name or other criteria. We used the first and last name of each public person in quotes as the function parameter; therefore, we performed 42 requests. However, as each query returned a maximum of 20 results, we had to query the API 
function repeatedly. As a result of the execution of the aforementioned procedure, we obtained a list of Twitter screennames corresponding to the names of the 42 public persons in question. Next, we used the API call "statuses/user timeline"; this call retrieves data on the 3200 most recent public Tweets of a user specified in the parameter. Data are represented as a JSON (JavaScript Object Notation) object containing a number of fields, such as status text, date, information on retweet, and so forth. We refer the reader to [45] for a detailed description of the object. The collected data were stored in MongoDB NoSQL database [46]. The result of this collection is presented in Table 1 below. The collection of profiles created in the name of the selected 42 personas resulted in a total of 28,529 Twitter accounts; their timeline posts totaled close to $36.6 \mathrm{M}$ tweets.

Table 1. Descriptive statistics for accounts and tweets collected per public persona

\begin{tabular}{lll}
\hline Statistics & Accounts & Tweets \\
\hline Mean & 679.26 & $871,177.1$ \\
Standard deviation & 400.62 & $846,194.3$ \\
Min. & 0 & 0 \\
Max. & 1,000 & $2,438,334$ \\
Median & 988 & $664,058.5$ \\
Sum & 28,529 & $36,589,439$
\end{tabular}

The second step collected tweets according to their hashtags using streaming API. For hashtags, the words "advertisement" and "sponsored" and their abbreviations were used. These two words were chosen because they were the two referred examples in both FTC regulations and WOMMA guidelines. The hashtags were chosen according to their usage frequency. A cross-check of the hashtags via tophashtags website [47] showed their popularity as demonstrated in Table 2 below.

Table 2. Popularity of advertisement hashtags

\begin{tabular}{llll}
\hline Hashtag & $\begin{array}{l}\text { Usage } \\
\text { Amount }\end{array}$ & Hashtag & $\begin{array}{l}\text { Usage } \\
\text { Amount }\end{array}$ \\
\hline \#ad & $3.38 \mathrm{M}$ & \#sp & $10.15 \mathrm{M}$ \\
\#advert & $152.0 \mathrm{~K}$ & \#spon & $101.2 \mathrm{~K}$ \\
\#advertisement & $580.8 \mathrm{~K}$ & \#sponsored & $577.5 \mathrm{~K}$
\end{tabular}

Hence, \#ad, \#sp, \#advertisement and \#sponsored hashtags were used for the collection: tweets that contained these hashtags were collected for 24 hours together with the profile information of their owners. As a result, nearly $72 \mathrm{~K}$ tweets were collected.

\subsection{Data analysis}

Analysis of the two data sets was done separately. Analysis of the first data set was conducted in two steps: The initial step distinguished unverified profiles that have advertisements in their tweets; the second step analyzed characteristics of these advertising profiles from qualitative aspects.

4.2.1. Analysis of the first data set. The initial phase of analysis commenced by querying tweets containing strings and hashtags that indicate an advertisement. Indication of the advertisement was established by the existence of "advertisement" and "sponsored" words, their abbreviations and hashtags. To this end, the queries extracted tweets that contained strings of "ad," "advert," "advertisement," "sp," "spon" and "sponsored"; and their hashtags "\#ad," "\#advert," "\#advertisement," "\#sp," "\#spon" and "\#sponsored." The numbers of tweets resulting from these queries are presented below in Table 3. Due to the high number of tweets in "ad" and "sp" files, they were downsized to their $10 \%$ by randomization. In the end, there were 3661 tweets in the ad and 854 tweets in the sp file. In conclusion, a total of 12,796 tweets were analyzed.

Table 3. Results of tweet queries

\begin{tabular}{llll}
\hline Query String & $\begin{array}{l}\text { Number of } \\
\text { Tweets }\end{array}$ & Query String & $\begin{array}{l}\text { Number of } \\
\text { Tweets }\end{array}$ \\
\hline ad & 36,793 & sp & 8,348 \\
\#ad & 2,262 & \#sp & 302 \\
advert & 1,427 & spon & 0 \\
\#advert & 12 & \#spon & 426 \\
advertisement & 960 & sponsored & 2,363 \\
\#advertisement & 6 & \#sponsored & 523
\end{tabular}

The resulting tweets from the queries were analyzed manually in order to distinguish whether they were advertisements. During this content analysis, tweets showing certain characteristics were eliminated. For instance, tweets in the "advert" and "advertisement" files mostly stated opinions about running advertisements, so they were not sponsored tweets. "Sp" mostly stood for São Paulo, or a political party. The word "sponsored" was also used to share externally sponsored events: announcing an event that was sponsored - these weren't classified as advert. Besides this, there were topics related to politics and government that included phrases such as "government sponsored," "state sponsored," "sponsored terror" and "sponsored bill." Advertisements for jobs were discarded, as it was assumed that they weren't sponsored. Tweets from 
accounts that were sharing their own sponsorship were not counted as sponsored. Posts related to giveaways or sweepstakes were also eliminated.

After screening the tweets, corresponding profiles were marked. Only unverified profiles were transferred to the second step of the analysis due to the assumption that verified profiles belonged to people who are assumed to act in the interest of the public.

In the second phase, compiled advertisement tweets and their associated profiles were analyzed once more to ensure that they were posting sponsored tweets. Profiles were coded and classified according to the purpose stated in each profile bio; tweets were coded according to the type of advertisements and Web links they posted. Profiles were also analyzed according to other profile information, which included profile picture, profile name, number of contacts (followers and followings), profile creation and last activity date, number of tweets, number of retweets, number of received retweets and posted URLs, photos and videos. The profiles that did not have multiple sponsored posts and did not otherwise indicate an advertising purpose in their bios were eliminated.

4.2.2. Analysis of the second data set. Prior to analysis of the second data set, it was first cleaned of retweets; then, the remaining tweets were downsized to a random $10 \%$ of the original, which resulted in 3360 tweets. Afterward, the analysis followed a different procedure compared to the first data set due to the amount of resulting profiles. The tweets were content-analyzed multiple times, first to distinguish advertisements from non-advertisements. Then, advertisement tweets were coded according to the links, the frequency of the same type of links they posted and the description of the profiles. For this, the links shortened by Twitter were reverted back to their original forms. Coding of the $\mathrm{Web}$ links enabled discovery of the services that were used for advertisements.

\section{Results}

The results of the analysis show that advertising accounts used miscellaneous resources. These resources were of both operand and operant nature. An overall classification of these resources resulted in two main groups: network externalities and online identity. Network externalities were further divided into direct and indirect network externalities. Furthermore, it was seen that the accounts used different combinations of these resources to extract utilitarian value from Twitter. In most cases, the accounts described the nature and purpose of the Twitter profile in their bios.

\subsection{Network externalities}

5.1.1. Direct network externalities. In the context of Twitter, direct network externalities stem from the social network reached through Twitter, in other words, the number of contacts. They enable users to accumulate potential social capital.

The analysis of the accounts showed that many of them had a very high number of followers or followings outside the boundaries identified by Zheng et al.'s study [35]: 250-1710. In the first data set, 73 advertising accounts were identified with a mean of 2281.88 followings and 30,976.93 followers, and a median of 1575 and 3691, respectively. Table 4 displays descriptive statistics for the number of followings and followers of advertising profiles in the first data set; Figure 2 shows the frequency of accounts (y-axis) per number of followers in the specified intervals (x-axis). As may be seen in the table, there is a substantial difference in the numbers between the followings and the followers. This might be due to the prominence of follower numbers for the social reach of advertisement tweets.

Table 4. Descriptive statistics for following and follower numbers in the first data set

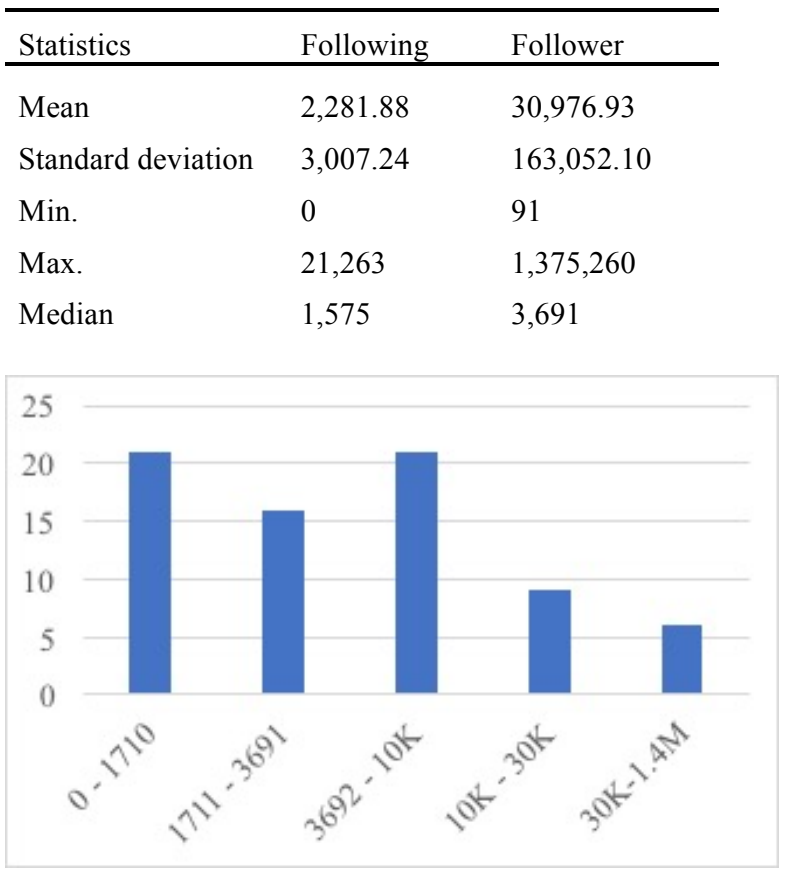

Figure 2. Frequency of accounts according to their follower numbers

5.1.2. Indirect network externalities. Twitter provides its users with extending indirect network externalities. An increasing number of consumers use Twitter in combination with other online services or 
complementary services. In the case of advertisements, these services may be grouped as other SMS, ecommerce websites and services combining their value offerings with the Twitter service.

Among the SMS that were used were YouTube, Instagram and paper.li. Accounts shared their content in multiple channels. E-commerce websites were used for the sale of merchandise. For instance, in the second data set, more than $10 \%$ of the tweets were linked to products sold on Amazon. Amazon and eBay have affiliate marketing programs called Amazon Associates and eBay Partners, respectively. Members of these programs may earn money when their website visitors or social followers click their advertisement links and make purchases [48, 49]. Others posted advertisements for merchandise sold on websites such as mercado livre, FUT Fanatics and others.

In the second data set, more than $55 \%$ of the tweets linked to short domains that differed from Twitter's link service. Therefore, we may argue that short domains seem to be a common method to increase webpage click-through rates (i.e., the ratio of clicks per views an ad receives).

Finally, there was also an account with a subscription to SponsoredTweets. SponsoredTweets is a service that brings together brands and consumers; in this connection, brands tap into consumers' networks for advertisements, and consumers get compensated for publishing commercials [50].

\subsection{Online identity}

The analysis showed that online identity was used as a resource in two ways. In the first case, the presentation of identities concentrated on professional skills such as being a designer or photographer. Also, it emphasized expertise in specific topics like beauty, fashion, decoration, recipes, gardening and fitness. Accordingly, the advertisements posted by these profiles related to the specialization of the profile owner. Some examples of bios belonging to these profiles are as follows:

Wife \& Mom. Creator \& Photographer. Sharing fun and frugal decor, recipes and gardening. @eBay Influencer. Shop my designs: @society6 and@etsy. \#TravelBlogger \& \#LifestyleBlogger | Aspiring

Expat. Thrill Seeker. Animal Collector. Wanna be

Chef. Follow along: https://t.co/SE1axfIijv

In the second case, public personas (e.g., G20 leaders), entities (e.g., sports clubs) or hobbies (e.g., gaming) were utilized in the construction of the Twitter profile. They named the profile in the name of these public personas or entities and described the purpose of the profile in the bio as providing news or a fandom base. Some of them sold merchandise (e.g., posters, tshirts) about these public identities or entities. Some examples of bios belonging to these profiles are as follows:

Los Angeles Lakers News

Latest news from r/gaming. Posts may include Amazon Affiliate Links, use them for your next purchases at no additional cost:

We post live news \& updates about Taylor Swift, her appearances, events and concerts. Stay tuned for photos, videos, set lists, \& more!

\#Collectibles About \#NBA \#Cleveland \#Cavaliers \#LeBronJames \#Sports \#Shopping \#Bargains \#Deals \#eBay \#Hot \#Sales \#Discount \#Deal \#Sporting \#Basketball \#LeBron

Daily updates on everything Demi Lovato! Demi rt'ed $7 / 12 / 11 \quad \& \quad 4 / 3 / 14 \quad{ }^{\text {тмЎ }}$ Store: https://t.co/QKeCT1xqyI

Latest Celebrity News, Celeb Gossip \&
Celebrities Stories. Get it all at http://t.co/DfSYnbolBy Watch videos with the latest celeb stories!!

The reason these accounts exist could be that identities of public personas and entities as symbols or representatives of particular ideologies or lifestyles could be used as a networked resource due to their potential value for attracting attention.

\section{Discussion}

Shaped by the social and cultural habits of its users, SMS are sensitive to changing customs surrounding them [51]. What's more, they provide their users with various resources that may be utilized for different purposes. These include but are not limited to their interface features and social nature. In the case of Twitter, hashtags, retweets and mentions-which enable communication within itself and across other platforms - or its programming interfaces that are open for developers are examples of these resources.

SMS are prone to be adapted for different purposes due to their user-generated content, network of users and the resources available to these systems. Although they might have been designed for hedonic use, their feature set enables their adaption for utilitarian purposes. Or, as people become more affiliated with the social media service, hedonic motivations lose importance, and utilitarian purposes, which are enabled through existing or add-on features, gain prominence in their usage [10]. Previous studies mainly concentrated on their hedonic use and have found that social networking sites are used for utilitarian purposes of immediate access and coordination [10]; they have also found that direct network externalities, in terms of people already known, and indirect network externalities fortify both their utilitarian and hedonic value [36]. 
However, neither SMS' utilitarian use nor the resources that contribute to this type of adaption have been widely studied. The aim of this study was to uncover what resources were employed in the utilitarian use of SMS, more specifically for monetary gains through sponsored advertisements. The study was conducted by qualitatively analyzing tweets and the Twitter accounts posting them.

The findings of this study show that people use a variety of resources to earn money via SMS. Network externalities is the first type of resource that contributes to monetary gains on Twitter. Direct network externalities in the form of a high number of contacts is beneficial for increasing social media reach. The number of followers and/or followings of advertising accounts in the first data set was outside the average number of contacts (250 to 1710) identified by [35]. This implies that, in contrast to the findings of Lin and Lu's [36] study, unfamiliar people contribute to the utilitarian use of SMS.

In terms of indirect network externalities, three types of resources were observed in the case of Twitter: other SMS, e-commerce services and services combining their offering with the Twitter service. Profiles used Twitter together with other SMS such as Instagram, paper.li and YouTube. In addition, there were many accounts with a high number of posts with links to products sold on Amazon or eBay. Furthermore, SponsoredTweets was another service used for monetizing SMS by people.

The ability to present one's identity in desired ways was another type of prominent resource employed in the utilitarian use of Twitter. There were two kinds of identity presentation in this case. In the first case, the accounts presented themselves as specializing in certain topics such as fashion, decoration or cooking. In the second case, the profiles were constructed to provide news about a human or nonhuman entity (e.g., celebrities, sports clubs). In a way, providing news about these entities was the value offering of the account owner for his or her followers.

In line with the framework presented in Figure 1, the utilitarian use of Twitter is argued to be enabled by various resources. In the case of sponsored content, people utilize network externalities and online identity as operand resources to get utilitarian value from the Twitter service. In addition, their creativity, skills and knowledge played the role of operant resources by combining the offerings of the Twitter service with other complementary services and contextual resources. This way, they both determined and proposed value on Twitter. Table 5 displays example combinations of these resources in the case of utilitarian adaption of Twitter through sponsored content.
Table 5. Resources and utilitarian use

\begin{tabular}{ll}
\hline Resources & Example \\
\hline Online Identity + Direct NE & Newsfeed about celebrities \\
\hline Online Identity + Direct NE & $\begin{array}{l}\text { Presentation of skills and } \\
\text { knowledge }\end{array}$ \\
\hline Indirect NE & $\begin{array}{l}\text { Advertisements via } \\
\text { SponsoredTweets }\end{array}$ \\
$\begin{array}{l}\text { Online Identity + Direct NE } \\
+ \text { Indirect NE }\end{array}$ & $\begin{array}{l}\text { Advertisements of } \\
\text { merchandise about } \\
\text { celebrities via eBay Partners }\end{array}$
\end{tabular}

\section{Conclusion}

This research applies ST and SDL to explain utilitarian use of SMS. Previous literature investigated effects of utilitarian and hedonic motivations on user acceptance, and emphasized usability and functionality when it comes to the utilitarian value of IS. In this study, IS are seen as social systems that provide interaction settings for people to engage in reproduced relations and regular practices. These relations or practices that are hedonic or utilitarian in nature shape IS use through different applications of contextual resources. In addition, this study shows that resources external to IS may also contribute to their utilitarian value. In this sense, the combination of ST and SDL provides a new perspective for IS research and explains how IS may be adapted for different uses other than their design purposes. Another contribution of the study is that it shows that the combination of resources may result in different values for different people. Therefore, this approach is also practical for forecasting alternative uses of IS. Furthermore, a resource-based analysis of IS may foresee its possible uses. It may be possible to minimize the unprecedented consequences of IS use by deconstructing its resources to anticipate how the service may be utilized and how it may be combined with other resources in its context of use.

Yet, no study is without limitations. First, we see some limitations arise from the study's Twitter data analysis. In other words, we do not at this moment have, for example, interview-based data to support the findings. However, collected data are in essence user generated; therefore, it does compare to self-reported surveys or open-ended questionnaires. The applied methodology here followed guidelines given for qualitative analysis of social media data in IS research [52]. This also provides uniqueness to the study and may be presented as an example for the use of rich social media data in qualitative research in the IS field. A second limitation arises from the selection of the search words (i.e., advertisement and sponsored). We acknowledge that this narrows down the search results; for instance, advertisement tweets labeled with 
"promotion" or non-labeled advertisements were not captured. However, the purpose of this study was not to cover all instances of sponsored tweets, but rather to illustrate the role of resources in utilitarian use of Twitter. We believe that studying posts with, for example, "promotion" would increase the variety and amount of resources that contribute to this kind of usage of the service. It should also be noted that we only analyzed Twitter use, and only for sponsored content, which limits the applicability of the findings to other SMS use and other IS use in general.

Future research may investigate different types of utilitarian uses of hedonic IS, such as the use of games for educational or health-care services. Otherwise, the reverse-hedonic adaption of utilitarian services - may be examined. For instance, crowdsourcing services are good candidates for this purpose. Other research may look into the impact of IS features on the hedonic or utilitarian use of IS. For instance, research may look into differences in feature-level use between utilitarian and hedonic adaptions.

\section{References}

[1] G. C. Whittaker, "Can Playing Video Games Be Your Full-Time Job?," Popular Science, 2015. Available: http://www.popsci.com/can-playing-video-gamesbe-your-full-time-job. [Accessed: 10-Mar-2017].

[2] J. Herrman, "How Sponsored Content Is Becoming King in a Facebook World," The New York Times, 2016. Available:

https://www.nytimes.com/2016/07/25/business/spon sored-content-takes-larger-role-in-mediacompanies.html. [Accessed: 22-Aug-2017].

[3] K. Morrison, "Sponsored Instagram Posts Average \$300 Each. Here's a Look at Who Makes More (or Less)," Adweek, 2017. Available:

http://www.adweek.com/digital/what-is-the-realcost-of-instagram-influence-infographics/. [Accessed: 22-Aug-2017].

[4] A. Griffin, "Facebook launches Marketplace, a new feature to let people buy things from friends and strangers," The Independent, 2016. Available: http://www.independent.co.uk/life-style/gadgetsand-tech/news/facebook-marketplace-buy-sell-siteebay-craigslist-a 7342711.html. [Accessed: 10-Mar2017].

[5] F. D. Davis, R. P. Bagozzi, and P. R. Warshaw, "Extrinsic and Intrinsic Motivation to Use Computers in the Workplace," Journal of Applied Social Psychology (22:14), 1992, pp. 1111-1132.

[6] H. van der Heijden, "User Acceptance of Hedonic Information Technology," MIS Quarterly (28:4), 2004, pp. 695-704.

[7] E. Karahanna, D. W. Straub, and N. L. Chervany, "Information Technology Adoption Across Time: A Cross-Sectional Comparison of Pre-Adoption and Post-Adoption Beliefs," MIS Quarterly (23:2), 1999, pp. 183-213.

[8] R. L. Thompson, C. A. Higgins, and J. M. Howell, "Influence of Experience on Personal Computer Utilization: Testing a Conceptual Model," Journal of Management Information Systems (11:1), 1994, pp. 167-187.

[9] M. Magni, M. S. Taylor, and V. Venkatesh, “"To play or not to play': A cross-temporal investigation using hedonic and instrumental perspectives to explain user intentions to explore a technology," International Journal of Human Computer Studies (68:9), 2010, pp. 572-588.

[10] C. Xu, S. Ryan, V. Prybutok, and C. Wen, "It is not for fun: An examination of social network site usage," Information \& Management (49:5), 2012, pp. 210217.

[11] T. L. Childers, C. L. Carr, J. Peck, and S. Carson, "Hedonic and utilitarian motivations for online retail shopping behavior," Journal of Retailing (77:4), 2001, pp. 511-535.

[12] A. Giddens, The constitution of society: Outline of the theory of structuration. Univ of California Press., 1984.

[13] S. L. Vargo and R. F. Lusch, "Evolving to a New Dominant Logic for Marketing," Journal of marketing (68:1), 2004, pp. 1-17.

[14] S. L. Vargo and R. F. Lusch, "Service-dominant logic: Continuing the evolution," Journal of the Academy of marketing Science (36:1), 2008, pp. 1-10.

[15] B. Edvardsson, P. Skålén, and B. Tronvoll, "Service Systems as a Foundation for Resource Integration and Value Co-Creation", Special Issue-Toward a better understanding of the role of value in markets and marketing, 2012, pp. 79-126.

[16] P. Berthon, L. F. Pitt, and R. T. Watson., "The World Wide Web as an advertising medium.," Journal of Advertising Research (36:1), 1996, pp. 43-54.

[17] The Economist, "Daily chart: Celebrities' endorsement earnings on social media," The Economist, 2016. Available:

http://www.economist.com/blogs/graphicdetail/2016 /10/daily-chart-9. [Accessed: 23-Feb-2017].

[18] Federal Trade Commission, ".com Disclosures: How to Make Effective Disclosures in Digital Advertising," 2013. Available:

https://www.ftc.gov/sites/default/files/attachments/p ress-releases/ftc-staff-revises-online-advertisingdisclosure-guidelines/130312dotcomdisclosures.pdf. [Accessed: 10-Mar-2017].

[19] WOMMA, "Best Practices for Transparency and Disclosure in Digital, Social, \& Mobile Marketing," 2013. Available: https://womma.org/ethics/smdisclosure/. [Accessed: 10-Mar-2017].

[20] J. Y. Park, K.-W. Lee, S. Y. Kim, and C.-W. Chung, "Ads by Whom? Ads about What? Exploring User Influence and Contents in Social Advertising," Proceedings of the first ACM conference on Online Social Networks - COSN'13, 2013, pp. 155-164.

[21] M. R. Jones and H. Karsten, "Giddens's Structuration Theory and Information Systems Research," MIS 
Quarterly (32:1), 2008, pp. 127-157.

[22] W. J. Orlikowski, "The Duality of Technology : Rethinking the Concept of Technology in Organizations," Organization Science (3:3), 1992, pp. 398-427.

[23] V. Venkatesh and S. A. Brown, "A longitudinal investigation of personal computers in homes: adoption determinants and emerging challenges," MIS Quarterly (25:1), 2001, pp. 71-102.

[24] B. J. Babin, W. R. Darden, and M. Griffin, "Work and/or Fun - Measuring Hedonic and Utilitarian Shopping Value," Journal of Consumer Research (20:4), 1994, pp. 644-656.

[25] J. F. Sherry Jr, "Dealers and Dealing in a Periodic Market: Informal Retailing in Ethnographic Perspective," Journal of Retailing (66:2), 1990, pp. 174-200.

[26] N. Tractinsky, A. S. Katz, and D. Ikar, "What is beautiful is usable," Interacting with Computers (13:2), 2000, pp. 127-145.

[27] E. L. Deci and R. M. Ryan, “The 'What' and 'Why' of Goal Pursuits: Human Needs and the SelfDetermination of Behavior," Psychological Inquiry (11:4), 2000, pp. 227-268.

[28] E. C. Hirschman and M. B. Holbrook, "Hedonic consumption: Emerging concepts, methods and propositions," The Journal of Marketing (46:3), 1982, pp. 92-101.

[29] D. S. Ardia, "Reputation in a Networked World : Revisiting the Social Foundations of Defamation Law," Harvard Civil Rights-Civil Liberties Law Review (45), 2010, pp. 261-328.

[30] T. Hilton and T. Hughes, "Co-production and selfservice: The application of Service-Dominant Logic," Journal of Marketing Management (29:7-8), 2013, pp. 861-881.

[31] B. M. L. Katz and C. Shapiro, "Network Externalities, Competition, and Compatibility," The American Economic Review (75:3), 1985, pp. 424-440.

[32] M. L. Katz and C. Shapiro, "Systems Competition and Network Effects," The Journal of Economic Perspectives (8:2), 1994, pp. 93-115.

[33] V. K. Tuunainen and T. Tuunanen, "IISI n - A model for analyzing ICT Intensive Service Innovations in nsided Markets," $44^{\text {th }}$ Hawaii International Conference on System Siences (HICSS), 2011, pp. $1-10$.

[34] C.-P. Lin and A. Bhattacherjee, "Elucidating Individual Intention to Use Interactive Information Technologies: The Role of Network Externalities," International Journal of Electronic Commerce (13:1), 2008, pp. 85-108.

[35] T. Zheng, M. J. Salganik, and A. Gelman, "How Many People Do You Know in Prison ?: Using Overdispersion in Count Data to Estimate Social Structure in Networks," Journal of the American Statistical Association (101:474), 2006, pp. 409423.

[36] K. Y. Lin and H. P. Lu, "Why people use social networking sites: An empirical study integrating network externalities and motivation theory,"
Computers in Human Behavior (27:3), 2011, pp. 1152-1161.

[37] quintly, "Social Media Analytics \& Competitor Benchmarking," 2017. Available: https://www.quintly.com/. [Accessed: 15-Apr2017].

[38] Hootsuite, "Twitter for business," 2016. Available: https://hootsuite.com/twitter. [Accessed: 15-Apr2017].

[39] G. Merchant, "Identity, Social Networks and Online Communication," E-Learning and Digital Media (3:2), 2006, pp. 235-244.

[40] J. Sundén, Material virtualities. New York: Peter Lang, 2003.

[41] H. Miller, "The Presentation of Self in Electronic Life : Goffman on the Internet," Embodied knowledge and virtual space conference (9), 1995.

[42] A. E. Marwick and D. Boyd, "I tweet honestly, I tweet passionately: Twitter users, context collapse, and the imagined audience," New Media \& Society (13:1), 2011, pp. 114-133.

[43] Twitter Counter, “Top 100 Most Followed Users on Twitter," 2017. Available: http://twittercounter.com/pages/100. [Accessed: 14Feb-2017].

[44] Twitter Inc., "GET users/search - Twitter Developers,” 2017. Available:

https://dev.twitter.com/rest/reference/get/users/searc h. [Accessed: 29-Apr-2017].

[45] Twitter Inc., “Tweets - Twitter Developers,” 2017. Available: https://dev.twitter.com/overview/api/tweets. [Accessed: 29-Apr-2017].

[46] MongoDB Inc., "MongoDB - The Leading NoSQL Database," 2017. Available: https://www.mongodb.com/leading-nosql-database. [Accessed: 29-May-2017].

[47] Top-Hashtags.com, "Top HashTags for the Internet," 2017. Available: https://top-hashtags.com/. [Accessed: 08-Mar-2017].

[48] Amazon.com Inc., “Amazon.com Associates: The web's most popular and successful Affiliate Program," Amazon Associates, 2017. Available: https://affiliate-program.amazon.com/. [Accessed: 02-May-2017].

[49] eBay Inc., "Share Your Passion," eBay Partner Network, 2017. Available: https://partnernetwork.ebay.com/. [Accessed: 02May-2017].

[50] IZEA Inc., "SponsoredTweets : The Creator Marketplace," 2017. Available: https://sponsoredtweets.com/. [Accessed: 12-Apr2017].

[51] A. Hermida, "Twittering the News: The emergence of ambient journalism," Journalism Practice (4:3), 2010, pp. 297-308.

[52] B. Mckenna, M. D. Myers, and M. Newman, "Social media in qualitative research: Challenges and recommendations," Information and Organization (27:2), 2017, pp. 87-99. 